\title{
The Relative Influence of Generic Essential Drugs and Nursing Staff Supplies on Access to Primary Healthcare Services in Burkina Faso: A Trivariate Probit Modeling Approach
}

\author{
Ibrahim Niankara \\ College of Business, Al Ain University of Science and Technology, P.O. Box: 112612, Abu Dhabi, UAE; Tel: \\ +97124444696 Ext: 539 ; Fax: +97124444304; E-mail: ibrahim.niankara@aau.ac.ae
}

\begin{abstract}
This study uses data from the pilot project "Community Monitoring for Better Health and Education Services Delivery Project" in Burkina Faso, to model the joint impact of generic essential drugs and nursing staff supplies constraints on access to primary health care in the country. The results show that statistical endogeneity of supply side constraints are present in the standard univariate probit specification of access to care. However, when accounted for, the resulting Trivariate Probit model shows that although shortages of generic essential drugs supply do not seem to constitute a significant barrier to access in Burkina Faso, shortages in nursing staff supply do. In fact, the likelihood of primary care access is reduced by $85.5 \%$ among those that reported having experienced a shortage in nursing staff, while paradoxically increasing by $60.3 \%$ among those that reported having experienced a shortage in generic essential drugs. A potential explanation for these findings is that overall the health care needs in the three surveyed regions in the country were more linked to primary health care services consumption from nurses, although further research would be important to clearly elucidate the position of health goods such as generic essential drugs.
\end{abstract}

Keywords: Access to Care, Burkina Faso, Generic Essential Drugs, Nursing staff, Trivariate Probit JEL: C12, C31, C51, I11, J22, N37 


\section{Introduction}

Health economics is the branch of science that uses economic principles and methods to deal with both health and health care as a good or service that is manufactured, or produced (Strauss and Thomas, 2007). Health care production requires the use of health care resources such as health care professionals, therapeutic materials and clinics to provide an amount of health care of a given quality (Graf et al., 1996). A key observation in health economics is that health resources are known to be limited in quantity, with no known bounds on the desired quantity of health outputs (Ly et al., 2014). This issue, known as the problem of scarcity of resources means that choices must be made about what health goods are produced, how they are produced and for whom they are produced (Morris et al., 2007). This also means that some people will get to consume the health care they need, while others won't. Hence equity issues arise, in relation to the fair distribution of and access to health care within the population (Haddad et al., 2004; Ridde, 2006).

Access to health care usually has two dimensions, access to health goods, and access to health services (Hill, 1977). Because health services require direct contact between service providers and end health consumers ( cannot be detached from its provider/supplier), while health goods as tangible objects (can be detached from their producers) do not require direct contact between goods providers and end consumers, the processes leading to resolving their shortages in a market place are somewhat different. In fact, health services shortages can usually be linked to shortages in health services providers (typically health care workers such as Doctors and Nurses), while shortages of health goods such as tangible essential drugs and medicines, may not necessarily be linked to a shortage of goods providers (typically pharmacies and drugs manufacturing companies) but instead due to poor sourcing in the health care system. This means that problems of health services shortages can be resolved by resolving shortages of health care workers(Ly et al., 2014), while problems of health goods shortages can be resolved by resolving sourcing issues within the health care system(Ridde et al., 2005; Silve and Ouedraogo, 2013).

Two major key players in the offer of health goods and services within Burkina Faso's Health care system are medical workers ( e.g. Nurses) and the CAMEG ${ }^{1}$ (see figure (2)).

\footnotetext{
${ }^{1}$ The Purchase Center for Generic Essential Drugs and Medical Consumables (CAMEG). Established by decree No 92-127 / SAN-ASF of 21 May 1992, the CAMEG started its activities in 1994 in the form of a project with the status of Public Institution of Industrial and Commercial Character, and the objective of not only contributing to the implementation of the Bamako Initiative in Burkina Faso, but of also putting generic essential drugs into circulation at affordable prices throughout the country, while guaranteeing the availability of quality generic essential medicines in accordance with national and international regulatory standards. In 1998 it was transformed into a non-profit association, with legal personality and financial autonomy in accordance with the provisions of Law 10-92 / ADP of 15 December 1992 under receipt No 98/053 / MATS / SG / DGAT / DLPAJ of 05 February 1998. Since then, CAMEG has expanded with a continuing decline in the prices and a better availability of essential medicines for the benefit of the populations.
} 
The health care system in Burkina Faso however, has long been affected by health human resources issues (shortages, and uneven geographical distribution of health care workers), which has led to the adoption in 2003, of a policy for the regionalization of health workers' recruitment in order to promote their better geographical distribution over all of the thirteen administrative regions (Ly et al., 2014). It has also been plagued with unreliable logistics management and information system, poor management capacity, lengthy acquisition procedures, financial resource deficit for specific procurement, and challenging coordination of health goods supply both upon arrival in the country and during distribution throughout the territory(Silve and Ouedraogo, 2013). Compounding these issues in 2016 were the strikes from dissatisfied health care workers, and lawsuits within the CAMEG(Some, 2016), creating instability in the functioning of the institution and putting a toll on the national health care system at large (see figure (1) for an Organizational chart of the Ministry of Health). In fact it created major shortages of essential medicines in the health facilities of the country ${ }^{2}$, and also costed the institution's image before its major partners, funders and international health organizations which have been providing support through development programs (Some, 2016).

These two recent shocks, by increasing the shortages in Health care workers and Generic essential medicines within health care facilities all over the country, are raising important questions with regard to the stability of the Health care system in Burkina Faso, and its readiness to meet the health care needs of the population. To the best of our knowledge, no prior study has looked at this problem before in Burkina Faso.

Therefore, the objective of this research is simply to Investigate the impact of supply side constraints on access to primary health care in Burkina Faso. More specifically we want to understand the joint impact of Generic Essential Drugs supply shortage and Nursing staff supply shortage on access to health care. In doing so, we seek to answer the following five basic questions:

- Q01: Does Generic Essential Drugs supply significantly affect access to primary health care in Burkina Faso?

- Q02: Does Nursing Staff supply significantly affect access to primary health care in Burkina Faso?

- Q03: Are the unobserved factors affecting Generic Essential Drugs supply significantly related to those affecting access to health care in Burkina Faso?

- Q04: Are the unobserved factors affecting Nursing staff supply significantly related to those affecting access to health care in Burkina Faso?

\footnotetext{
${ }^{2}$ since the CAMEG sources from its foreign suppliers on credit, the deficit of confidence created by the legal battle, has instilled major credit constraints
} 
- Q03: Are the effects of the two supply side constraints on access to primary health care significantly related to each other?

The maintained hypothesis are as follows:

- H01: Generic essential drugs supply shortages significantly reduce access to primary health care in Burkina Faso

- H02: Nursing staff supply shortage is also a significant barrier to the access of needed health care in Burkina Faso

- H03: The unobserved risks factors affecting generic essential drugs supply shortages significantly relate to those affecting access to health care in Burkina Faso ?

- H04: The unobserved risks factors affecting nursing staff supply shortages significantly relate to those affecting access to health care in Burkina Faso ?

- H05: The effect of the two supply side constraints on access to health care positively correlate in Burkina Faso

In our quest to test the above five hypothesis, the rest of the study is organized as follows: Section 2 presents Burkina Faso's Health care system, and state of health resources supply. Section 3 describes the data and the variables used in the econometric modeling. Section 4 presents the analytical strategy, while section 5 describes the results and section 6 concludes the analysis.

\section{Burkina Faso's Health Care System, and the State of Health Resources Supply}

Burkina Faso is a landlocked sahelian country in the loop of the Niger river with an area of $274,200 \mathrm{~km} 2$ and an economy based mainly on agriculture, which employs $84 \%$ of the population. As of 2012, Its GDP per capita was 335812 CFA Franc, with a real annual growth rate of $8 \%$ (DOMO et al., 2012) . Its Human Development Index is 0.3 for the same period according to the United Nation Developments Program (UNDP). The share of the total population living below the poverty line as of 2014 is $43.9 \%$, with $50.7 \%$ of the poor living in rural areas, against $19.9 \%$ in the urban areas INSD (2015).

The offer of Public health services in Burkina Faso is organized in three levels which ensure primary, secondary and tertiary cares. The first level in charge of primary care has two steps: (i) Centers for health and social promotion (CSPS) with a total of 1643 in 2014, and (ii) medical centers with surgical antenna (CMA) with a total of 47 in 2014. The second level in charge of secondary care is represented by the Regional Hospital Centers (CHR), which are the references for CMAs. The third level in charge of tertiary care consists of University Hospital Centers, and 
represents the highest reference level. Alongside the health facilities of the Ministry of Health, there are other public health facilities such as the health services centers of the armed forces. Burkina Faso also has private health facilities concentrated in the cities of Ouagadougou and Bobo-Dioulasso, with a total of 407 in 2014. The organizational chart (see figure (1)) describes the structure of the Ministry of health in Burkina Faso, while figure (2) presents the public supply circuit for health goods. Both figures suggest that the CAMEG plays a vital role in Burkina Faso's Health Care System.

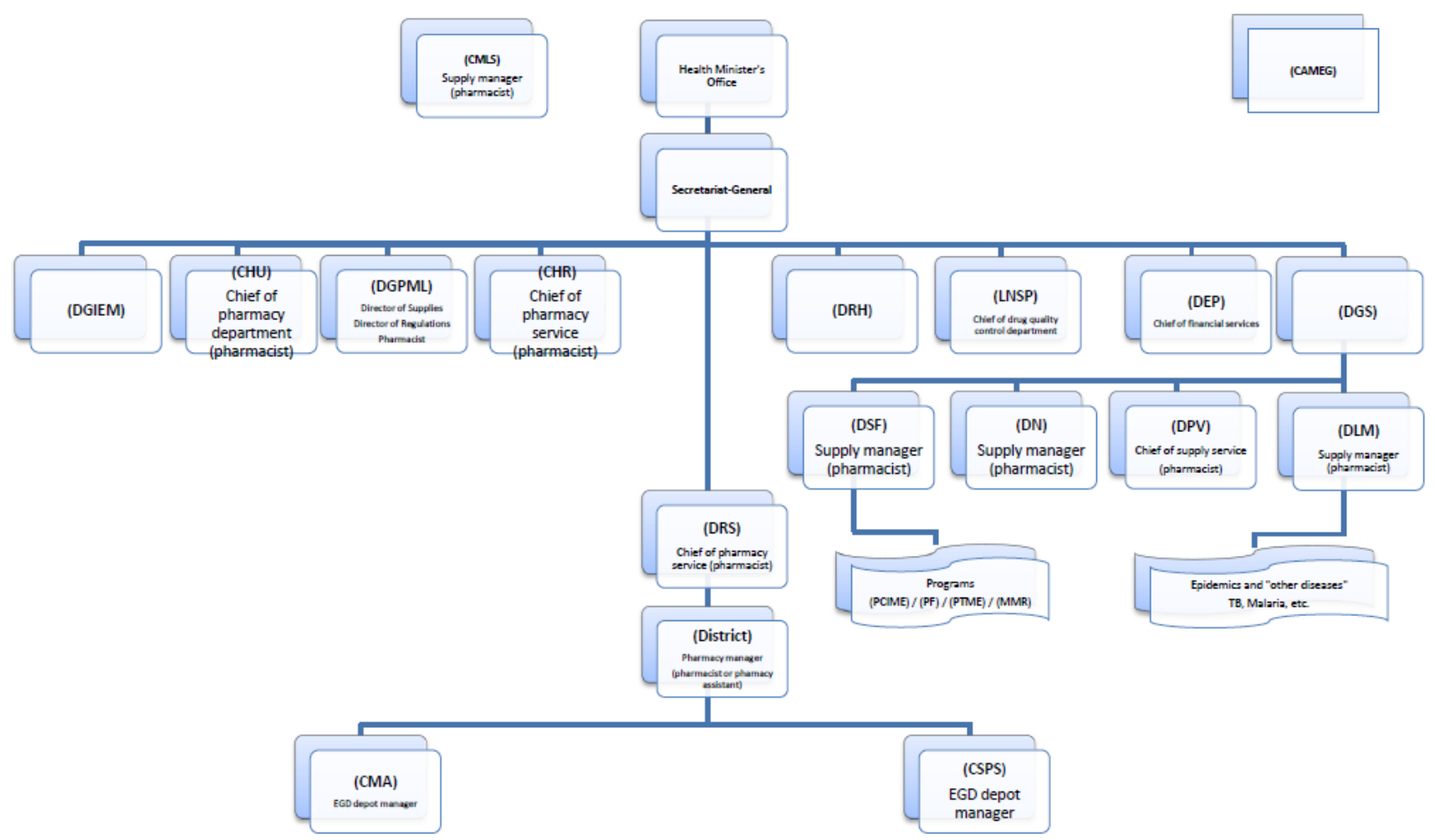

Figure 1: Organizational Chart for the Ministry of Health in Burkina Faso (source:(DOMO et al., 2012)) 


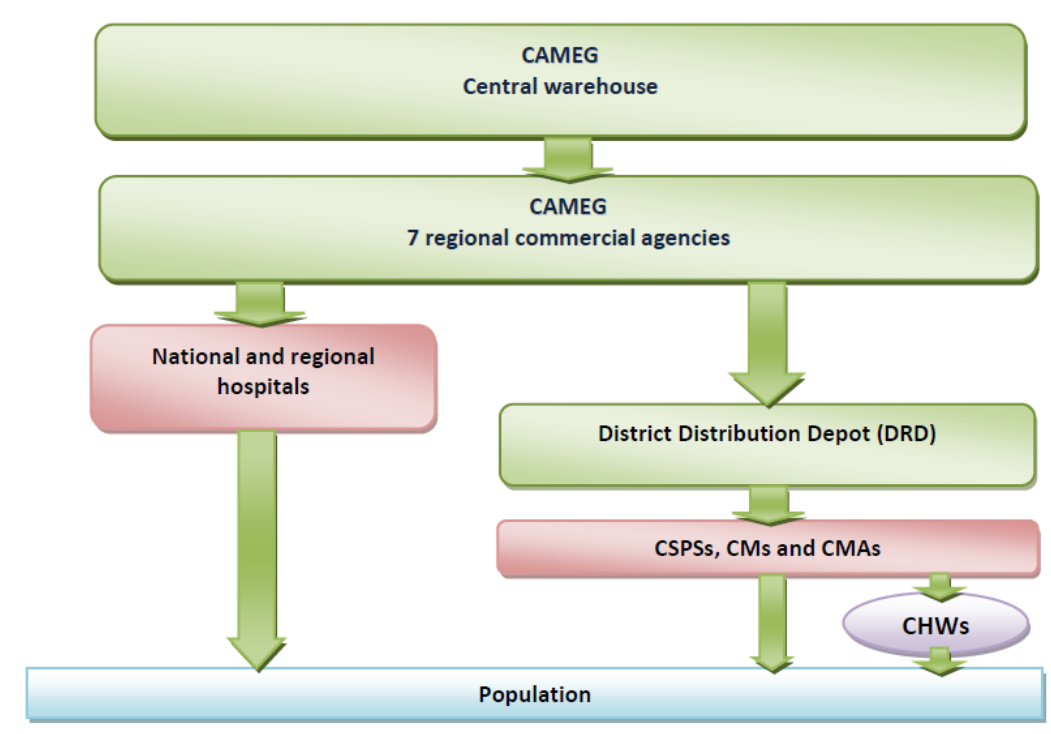

Figure 2: public supply circuit for health products in Burkina Faso (source:(DOMO et al., 2012)). From 1998 to 2016, the number of commercial agencies increased from 02 to 10 in eight regions of Burkina Faso; also the number of permanent staff increased from 40 in 1998 to 265 in 2016; sales revenues increased from 3245393756 CFA Franc in 1998 to 35805274285 CFA Franc in 2015; while the efforts put forth between 2001 and 2015 to reduce prices and make the medicines more affordable for the population reached 7177403073 CFA Franc (Some, 2016).

The current study focuses on three (Cascades, Central-Plateau, Sahel) of Burkina Faso's thirteen administrative regions (see figure(3)). For these three regions, table (.6) provides demographic characteristics, and suggests that the strongest growth rate in 2014 was recorded in the Cascades region $(4.8 \%)$, followed by the Sahel region (3.2\%), then the central-plateau (2.0\%). In terms of length of life, all three regions have a fairly identical life expectancy around 55 years, as shown by column 5 of the table.

In relation to the availability of nurses, table (.7) suggests that from 2012 to 2014, the number of registered nurses has decreased from 2830 to 2640 , while the number of state graduated nurses has increased from 3178 to 3718 , leading to an overall decrease in the ratio of population to nurses from 5280 to 4809 with the target by the national plan of health development being at 5000 persons/nurse. For generic essential Drugs supply, the percentage of drug facilities with no shortages decreased initially between 2012 and 2013 from 80.4\% to 75.9\%, and went back up in 2014 to $81.3 \%$ with the target by the national plan of health development being at $95 \%$. These figures suggest an increased shortage of both nurses and generic essential drugs, away from the targeted values by the national health development plan (PNDS).

In terms of the regional distribution of generic drugs supply in 2014, table(.8) suggest that only the Sahel region had a percentage of health care facilities without shortage(93.3\%) above the national average of $81.3 \%$. The two other regions had respectively $75.2 \%$ for the central plateau, 
and $72.0 \%$ for the Cascades region.

Looking at the state of shortages for the 20 most used essential drugs in the region, table $(.9)$ suggest that the rate of shortage was at its highest in the Sahel region at $1.4 \%$, followed by the central plateau at $0.9 \%$, then the cascades region at $0.1 \%$. However the average length of annual shortage in days was fairly close to 0 for the cascade region, with both the central plateau and the sahel regions at 0.1. All three regions were however, below national average on the rate of shortage, and the length of time spent in shortage which were respectively 1.6 and 0.2 .

Now focusing on the state of nursing staff supply for the three regions, from 2010 to 2014 as shown in table (10), the number of state graduated nurses increased initially between 2010 and 2011, from 2558 to 2852 , then decreased from there on to 2640 in 2014. The number of registered nurses on the other hand increased initially between 2010 and 2011, from 3054 to 3214, then decreased in 2012 to 3178, and from there on increased to 3718 in 2014.

Finally, the situation of the population to nurses ratio from 2010 to 2014 as presented in table (.11) suggests for state graduated nurses an initial decrease from 2803 to 2679 between 2010 and 2011, from which point it has increased to 2812 in 2014. On the other hand for registered nurses, this ratio increased initially between 2010 and 2012, from 5151 to 5280, and from there on decreased till 2014, reaching 4809.

Overall the statistics presented in the tables $(.6, .7, .8, .9,6.10, .11$ suggest the presence of clear shortages in both Nursing staff, and generic essential drugs in the three regions covered by our study. Therefore in the next sections we proceed to modeling the effects of these two health care supply shortages on access to primary health care by the populations living in those regions.

\section{Data and Variables Description}

The data used for our econometric analysis is from the 2011-2012 pilot project in Burkina Faso: "Community Monitoring for Better Health and Education Services Delivery Project (P121714; CMP)", which used a clustered-randomized controlled design to target 36 health facilities in nine poor rural municipalities within the three administrative regions of the Cascades, Central-Plateau, and the Sahel in Burkina Faso (see figure(3)). The study was conducted by the Higher Institute of Population Sciences (ISSP) at the University of Ouagadougou, with support from the Japanese Government and the World Bank, and aimed to increase the quality and quantity of health services through empowering, and stimulating individuals and communities to demand good governance and through increasing transparency and accountability of service providers(Holmlund, 2013b). Details information about the project and the base line data-set used here can be obtained from the world bank Micro-data Library Home (see (Holmlund, 2013a) 


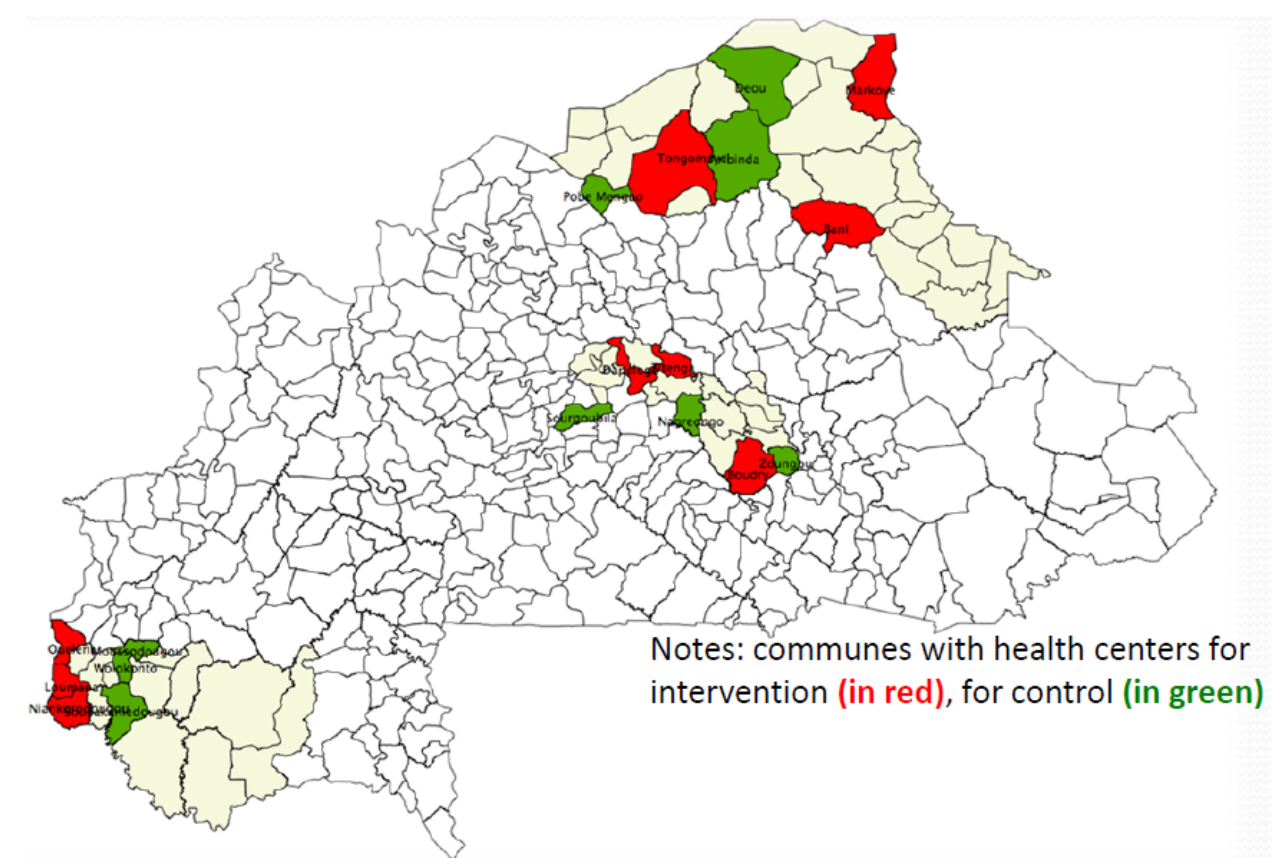

Figure 3: Regional coverage of the 2011-2012 Community Monitoring for Better Health and Education Services Delivery Survey in Burkina Faso (source:(Holmlund, 2013b))

\subsection{Dependents Variables}

LGDrugSup: The first binary variable used as an endogenous treatment variable, and taking the value 1 if the respondents replied "yes" to the question of whether or not, they encountered a shortage of Generic Essential Drugs at the health care facility.

LNurstaffSup: The second binary variable used as an endogenous treatment variable, and taking the value 1 if the respondents replied "yes" to the question of whether or not, they encountered a shortage of Nursing staff at the health care facility.

AccessCare: Represents the outcome variable capturing the respondent health care usage status. it is also binary and takes the value 1 if the respondent accessed the health care they needed, and 0 if they didn't.

\subsection{Independents variables}

The main independent variables of interest in this study are the supply constraint variables (LGDrugSup, LNurstaffSup) which as endogenous Binary treatment variables also play the role of Dependent variables in the trivariate probit formulation of model 04. The remaining control variables are described in the table(1) below. 
Table 1: Summary Description of the Variables used in the Econometric Modeling

\begin{tabular}{l|l|c|c}
\hline & 18156 & Mean & SD \\
\hline LGDrugSup & equal to 1 if lack of Generic Essential Drugs supply & 1.467 & 0.499 \\
LNurstaffSup & equal to 1 if lack of Nursing staff supply & 1.161 & 0.368 \\
AccessCare & equal to 1 if Accessed needed Health Care & 1.644 & 0.479 \\
SourceIncom & levels: 1 agriculture, 2 animal husbandry, & 1.391 & 1.070 \\
& 3 mining, 4 craft, 5 Small Business, 6 other & 1.398 & 0.643 \\
AttendSchool & levels: 1 never attended, 2 currently, 3 previously & 2.500 & 0.860 \\
languageInterv & levels: 1 french, 2 Moore, 3 fulfulde, 4 jula & 2.843 & 0.619 \\
religion & levels: 1 Catholic, 2 Protestantism, 3 Islam, 4 animism & 9.360 & 4.588 \\
hhSize & number of People living in the Household & 2.212 & 0.713 \\
region & levels: 1 Cascades, 2 Plateau-Central, 3 Sahel & 1.511 & 0.500 \\
sex & equal to 1 if female & 26.970 & 18.178 \\
age & age of the respondent in years & 1.498 & 0.500 \\
ExpCantPay & equal to 1 if health care is too expensive to pay & 1.536 & 0.499 \\
Lwaitgtime & equal to 1 if longtime waiting for care at health facility & 1.50 \\
\hline
\end{tabular}

Source: 2011-2012 Community Monitoring and Evaluation for Better Health and Education Services Delivery Survey, Burkina Faso

\section{Analytical Strategy}

Our Analytical strategy is grounded on the formulation of four Models which sequentially relaxe the classical assumptions of exogeneity and independence. Model 1 is a Binary Probit and assumes exogeneity of all predictors including the two treatment binary variables "essential drugs supply" and "nursing staff supply" shortages. Model 2 is a Bivariate Probit with only nursing staff supply exogeneity relaxed. Model 3 is also a Bivariate Probit with only drugs supply exogeneity relaxed. While model 4 is a Trivariate Probit with both nursing staff supply and Essential drugs supply exogeneities relaxed. We test the validity of this last specification using $\theta_{12}$, the correlation coefficient between the two endogenous treatments processes. If statistically significant, then the observed factors leading to the two endogeneities are related.

\subsection{Model 01: Exogenous Treatment effects}

For this, we rely on the index function formulation, where interest lies in explaining the underlying unobserved propensity to consume health services $y^{*}$ which is a continuous radom variable, however all we observe is the binary variable " $\mathrm{y}=$ AccessCare", which takes value 1 or 0 according to whether or not $y^{*}$ is positif. If we further let $t_{1}=$ LGDrugSup and $t_{2}=$ LNurstaffSup, then the natural regression model for $y^{*}$ in this index function formulation is given by:

$$
y^{*}=\beta^{\prime} X+\beta_{1} t_{1}+\beta_{2} t_{2}+\epsilon
$$


however, this model cannot be estimated since $y^{*}$ is unobserved, instead, we observe

$$
y=\left\{\begin{array}{lc}
1 & \text { if } y^{*}>0 \\
0 & \text { Otherwise }
\end{array}\right.
$$

Therefore, the probability that an individual access the care they need is given by:

$$
\begin{aligned}
\operatorname{Pr}\left[y=1 \mid t_{1}, t_{2}, X\right] & =\operatorname{Pr}\left[y^{*}>0\right] \\
& =\operatorname{Pr}\left[\beta^{\prime} X+\beta_{1} t_{1}+\beta_{2} t_{2}+\epsilon>0\right] \\
& =\operatorname{Pr}\left[-\epsilon<\beta^{\prime} X+\beta_{1} t_{1}+\beta_{2} t_{2}\right] \\
& =F\left(\beta^{\prime} X+\beta_{1} t_{1}+\beta_{2} t_{2}\right),
\end{aligned}
$$

where $F($.$) is the Cumulative Density function of -\epsilon$, which equals the cumulative density function of $\epsilon$ with symmetric density about 0 . In this index function representation, choosing a functional form for $F($.$) defines the type of behavioral model. The Probit model is obtained when we make$ the assumption that $F($.$) is the Normal cumulative density function. This formulation assumes all$ the variables explaining the propensity to use health care services are exogenous, and correspond to our first specification. It is estimated using maximum likelihood methods from the $\mathrm{R}$ library (R Core Team, 2015, glm(stats)). The results of this model are presented in table (2).

\subsection{Model 02: Endogenous Generic Essential Drugs Supply shortage effects}

Our second specification relaxes the exogeneity assumption for the binary treatment variable corresponding to the Generic Essential Drug supply shortage $\left(t_{1}\right)$. For this we define the continuous latent variable $\left(t_{1}^{*}\right)$ capturing the propensity of health care facilities to supply generic Essential Drugs, such that:

$$
t_{1}^{*}=\beta_{1}^{\prime} X_{1}+\epsilon_{1}
$$

with

$$
t_{1}=\left\{\begin{array}{lc}
1 & \text { if } t_{1}^{*}<=0 \\
0 & \text { Otherwise }
\end{array}\right.
$$

and the system of equations:

$$
\begin{aligned}
& t_{1}^{*}=\beta_{1}^{\prime} X_{1}+\epsilon_{1} \\
& y^{*}=\beta^{\prime} X+\beta_{2} t_{2}+\epsilon
\end{aligned}
$$


where the error terms $\left(\epsilon_{1}, \epsilon\right)$ are assumed to have a joint bivariate normal distribution with means 0 , variances 1 , and covariance coefficient $\theta$ to be estimated along with model parameters $\beta_{1}^{\prime}, \beta_{2}, \beta^{\prime}$. This formulation corresponds to our second specification, and is estimated using copula regression spline methods from the library (Wojtys et al., 2016, Section 2.2) in the R Statistical Software (R Core Team, 2015), with the results shown in table (3).

\subsection{Model 03: Endogenous Nursing Staff Supply shortage effects}

Our Third specification relaxes the exogeneity assumption for the binary treatment variable corresponding to the Nursing staff supply shortage $\left(t_{2}\right)$. For this we define the continuous latent variable $\left(t_{2}^{*}\right)$ capturing the propensity of health care facilities to have enough nurses, such that:

$$
t_{2}^{*}=\beta_{2}^{\prime} X_{2}+\epsilon_{2}
$$

with

$$
t_{2}=\left\{\begin{array}{lc}
1 & \text { if } t_{2}^{*}<=0 \\
0 & \text { Otherwise }
\end{array}\right.
$$

and the system of equations:

$$
\begin{aligned}
& t_{2}^{*}=\beta_{2}^{\prime} X_{2}+\epsilon_{2} \\
& y^{*}=\beta^{\prime} X+\beta_{1} t_{1}+\epsilon
\end{aligned}
$$

where the error terms $\left(\epsilon_{2}, \epsilon\right)$ are assumed to have a bivariate normal distribution with means 0 , variances 1 , and covariance coefficient $\theta$ to be estimated along with model parameters $\beta_{1}, \beta_{2}^{\prime}, \beta^{\prime}$. This formulation corresponds to our third specification, and is estimated using copula regression spline methods from the library (Wojtys et al., 2016, Section 2.2) in the R Statistical Software (R Core Team, 2015), with the results shown in table (4).

\subsection{Model 04: Endogenous Generic Essential Drugs Supply shortage, and Nursing staff supply} shortage effects

Finally our fourth specification relaxes both the exogeneity of "LGDrugSup" and "LNurstaffSup", leading to the system of three equations

$$
\begin{aligned}
& t_{1}^{*}=\beta_{1}^{\prime} X_{1}+\epsilon_{1} \\
& t_{2}^{*}=\beta_{2}^{\prime} X_{2}+\epsilon_{2} \\
& y^{*}=\beta^{\prime} X+\epsilon
\end{aligned}
$$


where the errors terms $\left(\epsilon_{1}, \epsilon_{2}, \epsilon\right)$ are assumed to have a trivariate normal distribution with means 0 , variances 1 , and covariance coefficients $\theta_{12} \theta_{13}$ and $\theta_{23}$ to be estimated along with the model parameters $\beta_{1}^{\prime}, \beta_{2}^{\prime}, \beta^{\prime}$.

This double endogeneity case corresponds to our fourth and last estimated specification, with the three latent (unobserved) continuous variables $t_{1}^{*}, t_{2}^{*}, y^{*}$ following the Trivariate Normal distribution:

$$
\left(\begin{array}{l}
t_{1}^{*} \\
t_{2}^{*} \\
y^{*}
\end{array}\right) \sim N_{3}\left[\left(\begin{array}{l}
\mu_{1} \\
\mu_{2} \\
\mu_{3}
\end{array}\right),\left(\begin{array}{ccc}
\sigma_{1} & \theta_{12} & \theta_{13} \\
& \sigma_{2} & \theta_{23} \\
& & \sigma_{3}
\end{array}\right)\right]
$$

where $\mu_{i}$ and $\sigma_{i}$ are respectively the mean and variance for $t_{1}^{*}, t_{2}^{*}, y^{*}$ and $\theta_{i j}$ are scalar correlation parameters. In this formulation each triplet of (treatment1, treatment2, Outcome) has $2 \times 2 \times 2=8$ potential outcomes. The joint probability for each of these eight outcomes is modeled with six systematic components following (Niankara and Niankara, 2017): the marginal probabilities $\operatorname{Pr}\left(t_{i 1}=1\right), \operatorname{Pr}\left(t_{i 2}=1\right)$, and $\operatorname{Pr}\left(y_{i}=1\right)$ and the correlation parameters $\theta_{12}, \theta_{13}$, and $\theta_{23}$ for the three marginal distributions. For identification purposes, the standard Probit model restricts the diagonal elements (variances) $\sigma_{i}, i=1,2,3$ in equation(11) to 1 . Each of these systematic components are modeled as functions of explanatory variables, and estimated using copula regression spline methods from the library (Wojtys et al., 2016, Section 2.2) in the R Statistical Software (R Core Team, 2015). The results are presented in table (5).

\section{Results}

Given the aim of the analysis, to evaluate the impact of health resources (Generic Essential Drugs, Nursing Staff ) supply shortages on access to primary health care, we've specified and estimated sequentially four regression models, with the results presented in tables(2) (3) (4) and (5).

\subsection{Model 01: Univariate Probit Results with Exogenous Treatments Effects}

Starting with the univariate probit results, as shown in table (2), the coefficient estimates in the second column suggest that while the nursing staff supply constraint is binding on the health care market in our three regions of study, the generic essential drugs supply constraint is non binding. More specifically, the positive coefficient value of 0.307 implies that respondents who report a nursing staff supply shortage are more likely to access the health care they need. This counter intuitive result may be explained by the fact that respondents' health care needs were unrelated to the health services offered by nurses. And the fact that the generic essential drugs supply shortage coefficient is not significant in the access to care equation implies also that it did not constitute an important barrier to access of needed health care. 
Considering regional heterogeneity in the effects of these two supply side constraints on access, we note that although the main effect of the drug supply shortage is not significant, its interacted effects with the regional Dummy variables show a significant effect in the central plateau region. Its negative value of -0.188 suggests that compared to the effect of generic drugs supply shortage in the Cascade region, the shortage observed in the central plateau region reduces relatively more access to primary health care. On the opposite, considering the regional heterogeneity in the effects of nursing staff supply shortage we note that the interacted effects are negative, despite its positive and significant main effect. This suggests that compared to the level of nursing staff supply shortage in the cascade region, the shortages observed in both the central plateau and Sahel regions reduce relatively more access to primary health care to the local populations.

Overall, the majority of the included control variables are seen to have the right signs and are statistically significant at the $\leq 5 \%$ significance level. Performing the Lagrange Multiplier test of endogeneity for the nursing staff supply shortage variable (Binary Variable) which has a null of no endogeneity, the p-value of 2.679426e-46 less than alpha of 0.05 suggests the presence of endogeneity. Therefore we proceed to fit a Bivariate Probit model to correct for this endogeneity as shown in the next section.

\subsection{Model 02: Bivariate Probit Results, with Endogenous Generic Essential Drugs Supply Effects}

With its endogenous essential drugs supply shortage, and exogenous nursing staff supply shortage effects, the results of model 2 are shown in table (3). The coefficient value of 0.868 for $\theta$ suggests a positive correlation between the unobserved factors affecting the shortage of generic essential drugs supply and the unobserved factors affecting access to primary health care (see figure(4)). The $95 \%$ confidence interval $(0.746,0.938)$, on this coefficient confirms its statistical significance and also the endogeneity previously detected by the Lagrange Multiplier test.

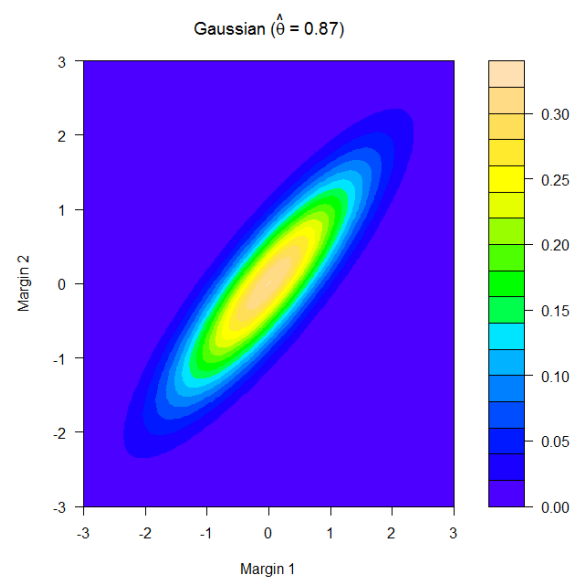

Figure 4: Bi-variate distribution of Generic Essential Drugs Supply Shortage and Access to Care 
Table 2: Univariate Probit Estimates of Access to Health Care in Burkina Faso

\begin{tabular}{l|cc}
\hline Diabetes & $\begin{array}{c}\text { Univariate } \\
\text { coeff. }\end{array}$ & $\begin{array}{c}\text { Probit (M1) } \\
\text { s.e. }\end{array}$ \\
\hline Const & $-0.726^{* * *}$ & $(0.121) \dagger$ \\
AttendSchool-current & 0.245 & $(0.027)$ \\
AttendSchool-previous & $0.208^{* * *}$ & $(0.039)$ \\
languageInterv-moore & $-0.638^{* * *}$ & $(0.043)$ \\
LanguageInterv-fulfulde & $-0.359^{* * *}$ & $(0.041)$ \\
LanguageInterv-jula & -0.046 & $(0.102)$ \\
Religion-protestant & $-0.661^{* * *}$ & $(0.144)$ \\
Religion-islam & -0.009 & $(0.037)$ \\
Religion-animism & $0.383^{* * *}$ & $(0.064)$ \\
HhSize & $0.016^{* * *}$ & $(0.002)$ \\
Region-centralPlat & 0.811 & $(0.118)$ \\
Region-sahel & $0.762^{* * *}$ & $(0.114)$ \\
Sex-female & -0.002 & $(0.020)$ \\
Age & $0.001^{*}$ & $(0.001)$ \\
LGDrugSup & -0.045 & $(0.054)$ \\
ExpCantPay & $-0.534^{* * *}$ & $(0.054)$ \\
Lwaitgtime & $0.217^{* * *}$ & $(0.051)$ \\
LNurstaffSup & $0.307^{* * *}$ & $(0.067)$ \\
Region-centralPlat*LGDrugSup & $-0.188^{* *}$ & $(0.062)$ \\
Region-sahel*LGDrugSup & -0.086 & $(0.063)$ \\
Region-centralPlat*ExpCantPay & $-0.126^{*}$ & $(0.063)$ \\
Region-sahel*ExpCantPay & $0.665^{* * *}$ & $(0.063)$ \\
Region-centralPlat*Lwaitgtime & 0.106 & $(0.060)$ \\
Region-sahel*Lwaitgtime & $-0.293^{* * *}$ & $(0.060)$ \\
Region-centralPlat*LNurstaffSup & $-0.684^{* * *}$ & $(0.080)$ \\
Region-sahel*LNurstaffSup & $-0.312^{* * *}$ & $(0.081)$ \\
& & \\
AIC & & 21903.48 \\
\hline
\end{tabular}

$\dagger$ standard deviation of the parameters in parentheses

†† The $95 \%$ confidence intervals for the theta correlations

${ }^{* * *}$ is $0.01 \%$ level significance; ${ }^{* *}$ is $1 \%$ level significance ; * is $5 \%$ level significance

Looking at the coefficient values of our treatment variables of interest(LGDrugSup, LNurstaffSup) in the Access to care equation of table (3), we notice that once again, the main effect of the generic essential drugs supply shortage is not significant, although that of the nursing staff supply shortage (-1.149) is negative and significant. This result seems to suggest that respondents who report nursing staff supply shortages are less likely to access the health care they need. 
Now accounting for regional heterogeneity in supply side constraints, we note that the relative interacted effects of generic essential drugs supply shortage is negative and significant in the centralplateau region (-0.130), while the effects of nursing staff supply shortage are positive in both the central plateau region $(-0.492)$ and the Sahel region (-0.361). This suggests that relative to those reporting nursing staff supply shortage in the cascades region, those doing so in the central plateau region and the Sahel region are relatively less likely to access the health care they need.

Overall the control variables in the access to health care equation and the generic drug supply treatment equation are all statistically significant at the $5 \%$ level, with some of those covariates used as exclusion restrictions in the treatment equation for identification purposes. As we move to perform the Lagrange multiplier test of endogeneity of generic essential drug supply shortage (Binary Variable), we get a p-value of $1.465844 \mathrm{e}-10$ which is less than alpha of 0.05 level of significance, therefore we reject the null and conclude the presence of endogeneity. We proceed to fit the Bivariate Probit model correcting for this endogeneity next.

\subsection{Model 03: Bivariate Probit Results, with Endogenous Nursing Staff Supply Effects}

With its endogenous nursing staff supply shortage, and exogenous essential drugs supply shortage effects, the results of model 3 are shown in table (4). The coefficient value of 0.669 for $\theta$ suggests a positive correlation between the unobserved factors affecting the shortage of nursing staff supply, and the unobserved factors affecting access to primary health care (see figure(5)). This coefficient is statistically significant as shown by the $95 \%$ confidence interval $(0.463,0.804)$, hence confirming also the endogeneity previously detected by the Lagrange Multiplier test.

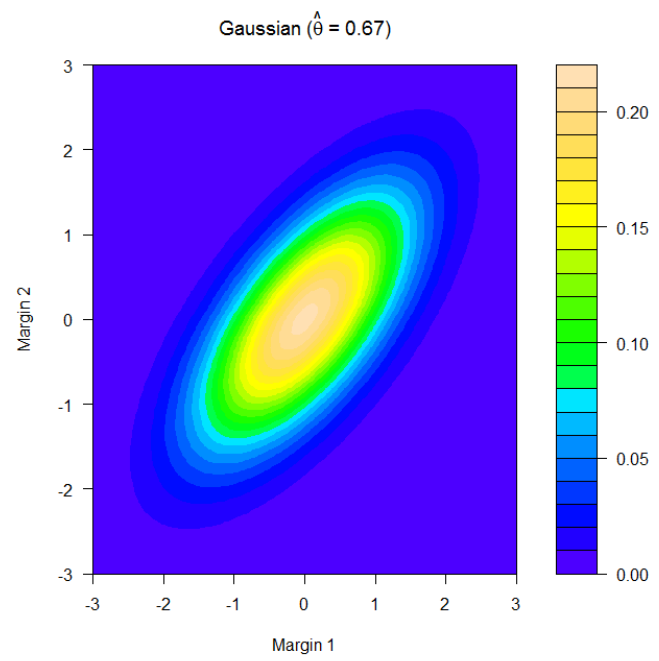

Figure 5: Bi-variate distribution of Nursing Staff Supply Shortage and Access to Care 
Looking at the coefficient values on our treatment variables of interest(LGDrugSup, LNurstaffSup) in the access to care equation of table (4), we note now that the main effects for both, the generic essential drugs supply shortage and the nursing staff supply shortage are significant. However, the generic essential drugs supply shortage has a negative effect $(-1.110)$ on access to care, while the nursing staff supply shortage variable presents a positive coefficient (0.264).

These results seem to suggest that respondents who reported a shortage of generic essential drugs supply are less likely to access the health care they need, while respondents who reported a nursing staff supply shortage have more chances of accessing the health care they need. This counter intuitive result for the later may be explained by the fact that respondents' health care needs were relatively unrelated to primary nursing care services, but more related to generic essential drugs.

Now considering regional heterogeneity in supply side constraints, we note that the relative effects of the generic essential drugs supply constraint is negative and significant (-0.135) in the central-plateau region alone, while the effect of nursing staff supply shortage is negative in both the central plateau region (-0.583) and the Sahel region (-0.254). These results therefore suggest that compared to those reporting generic essential drugs supply shortage in the Cascade region, the respondents doing so in the Central-plateau region have relatively less chances of accessing the health care they need. Similarly, relative to those reporting nursing staff supply shortage in the cascades region, the respondent doing so in the central plateau region and the Sahel region are relatively less likely to access the health care they need.

Overall the control variables in the access to health care equation and the generic nursing staff supply shortage (endogenous treatment) equation are all statistically significant at the $5 \%$ level, with some of the covariates used as exclusion restrictions in the treatment equation for identification purposes. Since both supply side constraints were independently identified to be endogenous in the access to care equation, our last specification in the form of a Trivariate Probit model takes into account both endogeneities. The results are presented in table (5).

\subsection{Model 04: Trivariate Probit Results}

The correlation coefficient values $\theta_{13}=0.713$ and $\theta_{23}=0.425$ in table (5), suggest that the unobserved factors affecting the access to care equation positively correlate with those from each supply side constraint. Also, the unobserved factors from the two supply side shortages positively correlate $\left(\theta_{12}=0.242\right)$.

Looking at the coefficient values of our variables of interest(LGDrugSup, LNurstaffSup) in the access to care equation of table (5), we note that the main effects for both, the generic essential drugs supply shortage (0.603) and the nursing staff supply shortage (-0.855) are significant. However, the nursing staff supply shortage has a negative effect on access to care, while the generic essential drug supply shortage presents a positive coefficient. 
These results seem to suggest that respondents who report a shortage of generic essential drugs supply are more likely to access the health care they need, while respondents' who reported a nursing staff supply shortage are less likely to access the health care they need. These further indicate the possibility that respondents' health care needs were relatively unrelated to generic essential drugs, but more related to primary nursing care.

Now considering regional heterogeneity in supply side shortages, we note that the relative interacted effect of generic essential drugs supply shortage is negative and significant only in the central-plateau region (-0.130), while the effect of the nursing staff supply shortage is negative in both the central plateau region (-0.531) and the Sahel region (-0.332). These results therefore suggest that compared to those reporting generic essential drugs supply shortage in the Cascade region, the respondents doing so in the Central-plateau region have relatively less chances of accessing the health care they need. Similarly, relative to those reporting nursing staff supply shortage in the cascades region, the respondent doing so in the central plateau region and the Sahel region are relatively less likely to access the health care they need.

Overall the majority of the control variables in the access to health care equation(outcome), the generic essential drugs supply shortage equation (endogenous treatment 1), and nursing staff supply shortage equation (endogenous treatment 2) are all statistically significant at the $5 \%$ level, with some of the covariates used as exclusion restrictions for identification purposes in the treatments equations.

\section{Conclusions}

The motivation for this empirical analysis was the desire to understand the impact of Supply side constraints on access to primary health care in Burkina Faso. More specifically we wanted to know how generic essential drugs supply shortage, and nursing staff supply shortage jointly affect access to primary health care in three of the thirteen regions of Burkina Faso. In doing so, we seeked to answer five basic questions: (1) Does generic essential drugs supply shortage significantly affect access to primary health care in Burkina Faso ? (2) Does nursing staff supply shortage significantly affect access to primary health care in Burkina Faso ? (3) Are the unobserved factors affecting generic essential drugs supply significantly related to those affecting access to health care in Burkina Faso ? (4) Are the unobserved factors affecting nursing staff supply significantly related to those affecting access to health care in Burkina Faso ? and finally in (5) Are the effects of the two supply side constraints on access to primary health care significantly related to each other ?

To this end, the paper used an analytical strategy going sequentially from a univariate probit model (which assumes exogeneity of all included explanatory variables), to bivariate probit models, and culminating with a trivariate probit model. This strategy allowed us to sequentially relax the exogeneity assumption linked to the generic essential drugs supply shortage alone (considered as the first treatment variable in our analysis) in the first bivariate probit specification, followed by the 
exogeneity assumption linked to the nursing staff supply shortage alone (considered as the second treatment variable in our analysis) in the second bivariate probit specification, and ending with the exogeneity of both the first and second treatment variables together in the trivariate probit specification. This sequential specification procedure also allowed us to test the five formulated hypotheses in the introduction, and provided us with the answers to the above five questions.

In fact, using the results from the last model (Trivariate Probit) in table(5), the statistically significant coefficient value of 0.603 for the variable (LGDrugSup) allows us to reject the first formulated hypthesis (H01), under which generic essential drugs supply shortages significantly reduce access to primary health care services in Burkina Faso. Therefore, we can conclude that the evidence is enough to suggest the opposite effect. Also in the same table(5), the statistically significant coefficient value of -0.855 for the variable (LNurstaffSup) allows us to fail to reject the second formulated hypothesis (H02), and therefore to conclude that the evidence is enough to suggest nursing staff supply shortages significantly reduce access to primary health care services in Burkina Faso. In relation to the third hypothesis (H03), the correlation coefficient value $\theta_{13}=0.713$ along with its $95 \%$ confidence intervall $(0.454,0.871)$ leads us to fail to reject this hypothesis and therefore to conclude that the evidence is enough to suggest that the unobserved risks factors affecting generic essential drugs supply shortages significantly relate to those affecting access to primary health care in Burkina Faso, and more specifically this relation is positive as shown by the figure(4). For the fourth hypothesis (H04), the correlation coefficient value $\theta_{23}=0.424$ along with its $95 \%$ confidence intervall $(0.133,0.653)$ leads us to also fail to reject this hypothesis and therefore to conclude that the evidence is also enough to suggest that the unobserved risks factors affecting nursing staff supply shortages significantly relate to those affecting access to primary health care in Burkina Faso, and more specifically this relation is positive as shown by the figure(5). Finally in relation to the fifth and last formulated hypothesis (H05), the correlation coefficient value $\theta_{12}=0.242$ along with its $95 \%$ confidence intervall $(0.214,0.261)$ leads us to also fail to reject this hypothesis and therefore to conclude that the evidence is enough in support of a positive correlation between the effects of the two supply side constraints on access to health care in Burkina Faso.

Overall the study has shown that although shortages of generic essential drugs supply do not seem to represent a statistically significant barrier to health care access, shortages in nursing staff supply however do put a significant constraint on access to primary health care in Burkina Faso. A potential explanation being that overall the health care needs in those three regions were more linked to primary health care services consumption from nurses, although further research would be important to elucidate the position of health goods such as generic essential drugs. In addition, an analysis of access controlling for the impact of the existing health infrastructure in the country would be a valuable direction for a future endeavor. As of now, the current results do point out the significance of health policies in line with a better supply and regional distribution of health care workers, including primary care nurses in Burkina Faso. 


\section{References}

DOMO, Y., LEZEAU, J.-P., REA, A.-C., Rogez, A., SAVADOGO, A., Silve, B., 2012. professionalization of the healthcare supply chain in west africa. Tech. rep., The Bioforce Development Institute, In partnership with The Reproductive Health Supplies Coalition, west African Regional Survey.

Graf, L., Hemmasi, M., Strong, K. C., 1996. Strategic analysis for resource allocation decisions in health care organizations. Journal of Managerial Issues, 92-107.

Haddad, S., Nougtara, A., Ridde, V., 2004. Les inégalités d'accès aux services de santé et leurs déterminants au burkina faso. Santé, société et solidarité 3 (2), 199-210.

Hill, T. P., 1977. On goods and services. Review of income and wealth 23 (4), 315-338.

Holmlund, M., 2013a. Community monitoring and evaluation for better health and education services delivery - baseline survey 2011-2012. URL http://microdata.worldbank.org/index.php/catalog/1550/study-description

Holmlund, M., 2013b. Score cards for service: Evaluating the impact of community monitoring of health and education services in burkina faso.

URL http://microdata.worldbank .org/index .php/catalog/1550/download/25665

INSD, 2015. Rapport enquete multisectorielle continue (emc) 2014: Profil de pauvreté et d'inégalités. Tech. rep., Institut national de la statistique et de la démographie (INSD), http://www.insd.bf/n/index.php/publications?id=151.

Ly, A., Kouanda, S., Ridde, V., 2014. Nursing and midwife staffing needs in maternity wards in burkina faso referral hospitals. Human resources for health 12 (1), 1.

Ministere, d. l. s., 2015. Annuaire statistique 2014. Tech. rep., Minitere de la Santé du Burkina Faso: Direction Générale des études et Des Statistiques Sectorielles.

Morris, S., Devlin, N., Parkin, D., 2007. Economic analysis in health care. John Wiley \& Sons.

Niankara, I., Niankara, A., 2017. The contribution of body mass index in the shared etiology of diabetes, hypertension and hyperlipidaemia: A semi-parametric trivariate probit modeling approach. Journal of Clinical Medicine and Therapeutics 2 (1).

R Core Team, 2015. R: A Language and Environment for Statistical Computing. R Foundation for Statistical Computing, Vienna, Austria.

URL https: //www.R-project.org/ 
Ridde, V., 2006. L'accès des indigents aux services de santé au burkina faso: un problème public? Lien social et Politiques (55), 149-163.

Ridde, V., Nitièma, A. P., Dadjoari, M., 2005. Améliorer l'accessibilité des médicaments essentiels génériques aux populations d'une région sanitaire du burkina faso. Cahiers d'études et de recherches francophones/Santé 15 (3), 175-182.

Silve, B., Ouedraogo, A., 2013. Professionalizing health logistics in burkina faso: challenges, implementation and sustainability. Public Health Research 3 (6), 157-161.

Some, P., 2016. Crise a la cameg : le personnel interpelle le premier ministre. URL http://news . aouaga.com/h/101728.html

Strauss, J., Thomas, D., 2007. Health over the life course. Handbook of development economics 4, $3375-3474$.

Wojtys, M., Marra, G., Radice, R., 2016. Copula regression spline sample selection models: the $\mathrm{r}$ package semiparsamplesel. Journal of Statistical Software 71 (6). 
Table 3: Bivariate Probit Estimates of Access to Care with Endogenous Essential Drugs Supply Shortage Effects

\begin{tabular}{|c|c|c|c|c|}
\hline & \multicolumn{4}{|c|}{ Bivariate $\quad$ Probit (M2) } \\
\hline & $\begin{array}{c}\text { LGDrugSup } \\
\text { Coeff. }\end{array}$ & s.e. & Coeff. & $\begin{array}{c}\text { AccessCare } \\
\text { s.e. }\end{array}$ \\
\hline Const & $-0.428^{* * *}$ & $(0.122)$ & -0.144 & $(0.114)$ \\
\hline AttendSchool-current & 0.001 & $(0.027)$ & $0.193^{* * *}$ & $(0.025)$ \\
\hline AttendSchool-previous & $0.086^{*}$ & $(0.039)$ & $0.207^{* * *}$ & $(0.033)$ \\
\hline languageInterv-moore & $-0.198^{* * *}$ & $(0.049)$ & $-0.610^{* * *}$ & $(0.042)$ \\
\hline LanguageInterv-fulfulde & -0.031 & $(0.048)$ & $-0.288^{* * *}$ & $(0.040)$ \\
\hline LanguageInterv-jula & $-0.457^{* * *}$ & $(0.115)$ & $-0.219^{*}$ & $(0.094)$ \\
\hline Religion-protestant & -0.028 & $(0.144)$ & $-0.514^{* * *}$ & $(0.123)$ \\
\hline Religion-islam & $-0.130^{* * *}$ & $(0.039)$ & -0.063 & $(0.034)$ \\
\hline Religion-animism & $-0.309^{* * *}$ & $(0.076)$ & $0.167^{* *}$ & $(0.062)$ \\
\hline HhSize & 0.003 & $(0.002)$ & $0.015^{* * *}$ & $(0.002)$ \\
\hline Region-centralPlat & $-0.257^{*}$ & $(0.117)$ & $0.547^{* * *}$ & $(0.109)$ \\
\hline Region-sahel & $-0.608^{* * *}$ & $(0.115)$ & $0.394^{* * *}$ & $(0.108)$ \\
\hline Sex-female & - & - & 0.002 & $(0.016)$ \\
\hline Age & - & - & $0.001^{*}$ & $(0.001)$ \\
\hline LGDrugSup & - & - & -0.051 & $(0.041)$ \\
\hline ExpCantPay & - & - & $-0.411^{* * *}$ & $(0.044)$ \\
\hline Lwaitgtime & - & - & $0.151^{* * *}$ & $(0.040)$ \\
\hline LNurstaffSup & - & - & $-1.149^{* * *}$ & $(0.076)$ \\
\hline Region-centralPlat*LGDrugSup & - & - & $-0.130^{* *}$ & $(0.048)$ \\
\hline Region-sahel*LGDrugSup & - & - & -0.043 & $(0.050)$ \\
\hline Region-centralPlat*ExpCantPay & - & - & -0.086 & $(0.047)$ \\
\hline Region-sahel*ExpCantPay & - & - & $0.510^{* * *}$ & $(0.053)$ \\
\hline Region-centralPlat*Lwaitgtime & - & - & $0.092^{* * *}$ & $(0.046)$ \\
\hline Region-sahel*Lwaitgtime & - & - & $-0.220^{* * *}$ & $(0.048)$ \\
\hline Region-centralPlat*LNurstaffSup & - & - & $-0.492^{* * *}$ & $(0.059)$ \\
\hline Region-sahel*LNurstaffSup & - & - & $-0.361^{* * *}$ & $(0.056)$ \\
\hline SourceIncom-ani & $0.435^{* * *}$ & $(0.035)$ & & \\
\hline SourceIncom-min & 0.031 & $(0.057)$ & & \\
\hline SourceIncom-craft & $0.486^{* * *}$ & $(0.09)$ & & \\
\hline SourceIncom-sBus & $0.143^{* *}$ & $(0.049)$ & & \\
\hline SourceIncom-other & $0.162^{*}$ & $(0.069)$ & & \\
\hline$\hat{\theta}$ & & & 0.868 & $(0.746,0.938)^{\dagger \dagger}$ \\
\hline$\hat{\tau}$ & & & 0.669 & $(0.536,0.774)$ \\
\hline AIC & & & 37660.19 & \\
\hline
\end{tabular}

$\dagger$ standard deviation of the parameters in parentheses

†† The $95 \%$ confidence intervals for the theta correlations

${ }^{* * *}$ is $0.01 \%$ level significance; ${ }^{* *}$ is $1 \%$ level significance ; ${ }^{*}$ is $5 \%$ level significance 
Table 4: Bivariate Probit Estimates of Access to Health Care with Endogenous Nurse Supply Shortage Effects

\begin{tabular}{|c|c|c|c|c|}
\hline & $\begin{array}{c}\text { LNurstaffSup } \\
\text { Coeff. }\end{array}$ & Bivariate & $\begin{array}{c}\text { Probit (M3) } \\
\text { Coeff. }\end{array}$ & $\begin{array}{c}\text { AccessCare } \\
\text { s.e. }\end{array}$ \\
\hline Const & $0.741^{* * *}$ & $(0.110)$ & 0.198 & $(0.169)$ \\
\hline AttendSchool-current & $0.130^{* * *}$ & $(0.023)$ & $0.260^{* * *}$ & $(0.025)$ \\
\hline AttendSchool-previous & 0.036 & $(0.034)$ & $0.189^{* * *}$ & $(0.034)$ \\
\hline languageInterv-moore & $0.091^{*}$ & $(0.042)$ & $-0.503^{* * *}$ & $(0.051)$ \\
\hline LanguageInterv-fulfulde & $-0.393^{* * *}$ & $(0.041)$ & $-0.459^{* * *}$ & $(0.039)$ \\
\hline LanguageInterv-jula & -0.620 & $(0.104)$ & $-0.269^{* *}$ & $(0.100)$ \\
\hline Religion-protestant & 0.171 & $(0.105)$ & $-0.497^{* * *}$ & $(0.134)$ \\
\hline Religion-islam & $-0.122^{* * *}$ & $(0.034)$ & -0.064 & $(0.035)$ \\
\hline Religion-animism & -0.110 & $(0.061)$ & $0.273^{* * *}$ & $(0.064)$ \\
\hline HhSize & $0.017^{* * *}$ & $(0.002)$ & $0.021^{* * *}$ & $(0.002)$ \\
\hline Region-centralPlat & $-1.033^{* * *}$ & $(0.108)$ & $0.280^{*}$ & $(0.138)$ \\
\hline Region-sahel & $-0.820^{* * *}$ & $(0.105)$ & $0.322^{* * *}$ & $(0.128)$ \\
\hline Sex-female & - & - & -0.002 & $(0.017)$ \\
\hline Age & - & - & $0.001^{*}$ & $(0.001)$ \\
\hline LGDrugSup & - & - & $-1.110^{* * *}$ & $(0.137)$ \\
\hline ExpCantPay & - & - & $-0.452^{* * *}$ & $(0.051)$ \\
\hline Lwaitgtime & - & - & $0.199^{* * *}$ & $(0.043)$ \\
\hline LNurstaffSup & - & - & $0.264^{* * *}$ & $(0.059)$ \\
\hline Region-centralPlat*LGDrugSup & - & - & $-0.135^{*}$ & $(0.054)$ \\
\hline Region-sahel*LGDrugSup & - & - & -0.044 & $(0.055)$ \\
\hline Region-centralPlat*ExpCantPay & - & - & $-0.105^{*}$ & $(0.054)$ \\
\hline Region-sahel*ExpCantPay & - & - & $0.563^{* * *}$ & $(0.061)$ \\
\hline Region-centralPlat*Lwaitgtime & - & - & 0.077 & $(0.052)$ \\
\hline Region-sahel*Lwaitgtime & - & - & $-0.261^{* * *}$ & $(0.051)$ \\
\hline Region-centralPlat*LNurstaffSup & - & - & $-0.583^{* * *}$ & $(0.073)$ \\
\hline Region-sahel*LNurstaffSup & - & - & $-0.264^{* * *}$ & $(0.071)$ \\
\hline SourceIncom-ani & $-0.243^{* * *}$ & $(0.035)$ & & \\
\hline SourceIncom-min & $0.290^{* * *}$ & $(0.055)$ & & \\
\hline SourceIncom-craft & $-0.281^{* *}$ & $(0.100)$ & & \\
\hline SourceIncom-sBus & 0.047 & $(0.047)$ & & \\
\hline SourceIncom-other & - 0.129 & $(0.063)$ & & \\
\hline$\hat{\theta}$ & & & 0.669 & $(0.463,0.804)^{\dagger \dagger}$ \\
\hline$\hat{\tau}$ & & & 0.466 & $((0.306,0.594)$ \\
\hline $\mathrm{AIC}$ & & & 46234.84 & \\
\hline
\end{tabular}

$\dagger$ standard deviation of the parameters in parentheses

†† The $95 \%$ confidence intervals for the theta correlations

${ }^{* * *}$ is $0.01 \%$ level significance; ${ }^{* *}$ is $1 \%$ level significance ; ${ }^{*}$ is $5 \%$ level significance 
Table 5: Trivariate Probit Estimates of Access to Health Care in Burkina Faso

\begin{tabular}{|c|c|c|c|c|c|c|}
\hline & \multirow{2}{*}{\multicolumn{2}{|c|}{ LGDrugSup }} & \multicolumn{2}{|c|}{ Trivariate $\quad$ Probit (M4) } & \multirow[b]{3}{*}{ Coeff. } & \multirow[b]{2}{*}{ AccessCare } \\
\hline & & & & LNurstaffSup & & \\
\hline & Coeff. & s.e. & Coeff. & s.e. & & s.e. \\
\hline Const & $-0.452^{* * *}$ & $(0.120) \dagger$ & $0.787^{* * *}$ & $(0.112)$ & 0.181 & $(0.205)$ \\
\hline AttendSchool-current & -0.004 & $(0.027)$ & $0.130^{* * *}$ & $(0.023)$ & $0.229^{* * *}$ & $(0.028)$ \\
\hline AttendSchool-previous & $0.084^{*}$ & $(0.039)$ & 0.036 & $(0.034)$ & $0.211^{* * *}$ & $(0.034)$ \\
\hline languageInterv-moore & $-0.188^{* * *}$ & $(0.050)$ & $0.092^{*}$ & $(0.042)$ & $-0.583^{* * *}$ & $(0.051)$ \\
\hline LanguageInterv-fulfulde & -0.020 & $(0.049)$ & $-0.390^{* * *}$ & $(0.041)$ & $-0.378^{* * *}$ & $(0.050)$ \\
\hline LanguageInterv-jula & 0.447 & $(0.113)$ & $-0.659^{* * *}$ & $(0.107)$ & $-0.301^{* * *}$ & $(0.103)$ \\
\hline Religion-protestant & -0.052 & $(0.123)$ & 0.172 & $(0.106)$ & $-0.521^{* *}$ & $(0.131)$ \\
\hline Religion-islam & $-0.132^{* * *}$ & $(0.039)$ & $-0.127^{* * *}$ & $(0.033)$ & $-0.078^{*}$ & $(0.035)$ \\
\hline Religion-animism & $-0.342^{* * *}$ & $(0.077)$ & $-0.125^{*}$ & $(0.061)$ & $0.187^{* *}$ & $(0.066)$ \\
\hline HhSize & 0.004 & $(0.002)$ & $0.018^{* * *}$ & $(0.002)$ & $0.019^{* * *}$ & $(0.003)$ \\
\hline Region-centralPlat & $-0.248^{*}$ & $(0.117)$ & $-1.074^{* * *}$ & $(0.110)$ & $0.374^{*}$ & $(0.150)$ \\
\hline Region-sahel & $-0.594^{* * *}$ & $(0.114)$ & $-0.853^{* * *}$ & $(0.108)$ & $0.297^{*}$ & $(0.133)$ \\
\hline Sex-female & - & - & - & - & -0.000 & $(0.017)$ \\
\hline Age & - & - & - & - & $0.001^{* * *}$ & $(0.001)$ \\
\hline LGDrugSup & - & - & - & - & $0.603^{*}$ & $(0.249)$ \\
\hline ExpCantPay & - & - & - & - & $-0.439^{* * *}$ & $(0.049)$ \\
\hline Lwaitgtime & - & - & - & - & $0.164^{* * *}$ & $(0.044)$ \\
\hline LNurstaffSup & - & - & - & - & $-0.855^{* * *}$ & $(0.189)$ \\
\hline Region-centralPlat*LGDrugSup & - & - & - & - & $-0.130^{*}$ & $(0.052)$ \\
\hline Region-sahel*LGDrugSup & - & - & - & - & -0.061 & $(0.052)$ \\
\hline Region-centralPlat*ExpCantPay & - & - & - & - & -0.094 & $(0.051)$ \\
\hline Region-sahel*ExpCantPay & - & - & - & - & $0.546^{* * *}$ & $(0.058)$ \\
\hline Region-centralPlat*Lwaitgtime & - & - & - & - & 0.096 & $(0.050)$ \\
\hline Region-sahel*Lwaitgtime & - & - & - & - & $-0.231^{* * *}$ & $(0.051)$ \\
\hline Region-centralPlat*LNurstaffSup & - & - & - & - & $-0.531^{* * *}$ & $(0.069)$ \\
\hline Region-sahel*LNurstaffSup & - & - & - & - & $-0.332^{* * *}$ & $(0.067)$ \\
\hline SourceIncom-ani & 0.435 & $(0.039)$ & $0.210^{* * *}$ & $(0.038)$ & & \\
\hline SourceIncom-min & -0.055 & $(0.065)$ & $-0.323^{* * *}$ & $(0.057)$ & & \\
\hline SourceIncom-craft & $0.475^{* * *}$ & $(0.105)$ & $0.240^{*}$ & $(0.108)$ & & \\
\hline SourceIncom-sBus & $0.160^{* *}$ & $(0.053)$ & -0.074 & $(0.049)$ & & \\
\hline SourceIncom-other & $0.189^{*}$ & $(0.075)$ & 0.108 & $(0.068)$ & & \\
\hline$\hat{\theta}_{12}$ & & & & & 0.242 & $(0.214,0.261)$ \\
\hline$\hat{\theta}_{13}$ & & & & & 0.713 & $(0.454,0.871)$ \\
\hline$\hat{\theta}_{23}$ & & & & & 0.424 & $(0.133,0.653)$ \\
\hline AIC & & & & & 61725.21 & \\
\hline
\end{tabular}

$\dagger$ standard deviation of the parameters in parentheses

†† The $95 \%$ confidence intervals for the theta correlations

${ }^{* * *}$ is $0.01 \%$ level significance; ${ }^{* *}$ is $1 \%$ level significance ; ${ }^{*}$ is $5 \%$ level significance 
Table .6: Demographic characteristics for the regions of Burkina Faso covered by our study

\begin{tabular}{l|cccc}
\hline Regions & Annual Growth Rate & Gross Rate of Birth & Gross Rate of Death & Life Expectancy at Birth \\
\hline & $(\%)$ & (in 1000) & (in 1000) & ( in years ) \\
\hline Cascades & 4.8 & 46.9 & 12.2 & 54.3 \\
Central-Plateau & 2.0 & 46.0 & 13.2 & 55.6 \\
Sahel & 3.2 & 48.5 & 11.9 & 55.1 \\
& & & & \\
\hline
\end{tabular}

Source: Adapted from the 2014 Statistical Yearbook in Burkina Faso Ministere, 2015).

Table .7: Synthesis of the Indices from the 2011-2020 National Plan of health Development (PNDS)

\begin{tabular}{l|cccc}
\hline Indicator & Level & Level & Level & Target \\
\hline & 2012 & 2013 & 2014 & 2014 \\
\hline Ratio of Population/Nurse & 5280 & 4965 & 4809 & 5000 \\
\% of Health facilities with no Drug Shortage & 80.4 & 75.9 & 81.3 & $\geq 95$ \\
Number of Registered Nurses & 2830 & 2707 & 2640 & \\
Number of State Graduated Nurses & 3178 & 3489 & 3718 & \\
& & & & \\
\hline
\end{tabular}

Source: Adapted from the 2014 Statistical Yearbook in Burkina Faso Ministere, 2015.

Table .8: Availability of Generic Essential Drugs in Health Care Facilities in 2014

\begin{tabular}{l|ccc}
\hline Regions /Districts & $\begin{array}{c}\text { Number of Health Care } \\
\text { Facilities }\end{array}$ & $\begin{array}{c}\text { Number of Health Care } \\
\text { Facilities without Shortage }\end{array}$ & $\begin{array}{c}\text { Percentage of Health Care } \\
\text { Facilities without Shortage }\end{array}$ \\
\hline Cascades & 82 & 59 & 72.0 \\
Central-Plateau & 133 & 100 & 75.2 \\
Sahel & 90 & 84 & 93.3 \\
Total in Burkina Faso & 1836 & 1493 & 81.3 \\
\hline
\end{tabular}

Source: Adapted from the 2014 Statistical Yearbook in Burkina Faso (Ministere, 2015). 
Table .9: State of Shortages of the 20 most used Generic Essential Drugs from Health Care Facilities in 2014

\begin{tabular}{l|cccc}
\hline Regions & $\begin{array}{c}\text { Number of Sampled } \\
\text { Facilities/region }\end{array}$ & $\begin{array}{c}\text { Rate of Shortage } \\
\text { (in \%) }\end{array}$ & $\begin{array}{c}\text { Average Length of } \\
\text { Annual Shortage (in Days) }\end{array}$ & $\begin{array}{c}\text { Share of Sampled Facilities } \\
\text { with Shortage/region }\end{array}$ \\
\hline Cascades & 9 & 0.1 & 0.0 & 1.4 \\
Central-Plateau & 9 & 0.9 & 0.1 & 10.2 \\
Sahel & 12 & 1.4 & 0.1 & 11.8 \\
National Average & 189 & 1.6 & 0.2 & 11.9 \\
\hline
\end{tabular}

Source: Adapted from the 2014 Statistical Yearbook in Burkina Faso(Ministere, 2015).

Table .10: Changes in the Number of Nursing Staff Supply from 2010 to 2014 in Burkina Faso

\begin{tabular}{l|ccccc}
\hline & 2010 & 2011 & 2012 & 2013 & 2014 \\
\hline Number of Registered Nurses & 3054 & 3214 & 3178 & 3489 & 3718 \\
& & & & & \\
Number of State Graduated Nurses & 2558 & 2852 & 2830 & 2707 & 2640 \\
& & & & & \\
\hline
\end{tabular}

Source: Adapted from the 2014 Statistical Yearbook in Burkina Faso Ministere, 2015).

Table .11: Ratio of population to Nurses from 2010 to 2014 in Burkina Faso

\begin{tabular}{l|ccccc}
\hline Total Population & 2010 & 2011 & 2012 & 2013 & 2014 \\
Ratio of Population / Registered Nurses & 5151 & 5056 & 5280 & 4965 & 4809 \\
Ratio of Population / State Graduated Nurses & 2803 & 2679 & 2793 & 2796 & 2812 \\
\hline
\end{tabular}

Source: Adapted from the 2014 Statistical Yearbook in Burkina Faso Ministere, 2015). 